\title{
Controller Design of a Novel Power Conditioning System with an Energy Storage Device for Renewable Energy Sources under Grid-Connected Operation
}

\author{
Sun-Jae Park ${ }^{*}$, Hwa-Seok Lee*, Chan-In Kim*, Joung-Hu Park ${ }^{\dagger}$, Hee-Jong Jeon*, and Jeongduk Ryeom*
}

$\dagger^{\dagger \star}$ Dept. of Electrical Engineering, Soongsil University, Seoul, Korea

\begin{abstract}
As a result of the depletion of fossil fuels and environmental contamination, it has become important to use renewable energy. For the stable utilization of renewable energy sources, energy storage devices must be used. In addition, renewable and distributed power sources with energy storage devices must operate stably under grid-connected mode. This paper proposed dynamic response modeling for renewable power generation systems including a charger/discharger with an energy storage device in order to derive a method to guarantee stable operation while fully utilizing the energy from the energy storage device. In this paper, the principle operation and design guidelines of the proposed scheme are presented, along with a performance analysis and simulation results using MATLAB and PSIM. Finally, a hardware prototype of a $1 \mathrm{~kW}$ power conditioning system with an energy storage device has been implemented for experimental verification of the proposed converter system.
\end{abstract}

Key words: Bypass diode, Energy storage, Grid-connected, High efficiency, Small-signal modelling

\section{INTRODUCTION}

Due to the depletion of fossil fuels and the severe effects of environmental contamination, the need for renewable energy sources has become more important than ever. After issuing a promising solution, many renewable energy sources such as solar energy and wind power systems have been studied intensively. Since the power output from renewable energy sources is dominated by environmental circumstances, the state of power generation has been very unstable and the operation time has been quite restricted by specific conditions. For these reasons, the demands of the energy storage devices applied to renewable energy systems is increasing in order to efficiently use renewable energy sources [1]-[9].

When generating insufficient output power from renewable energy sources, the insufficient energy of the load can be supplied by the storage device. On the other hand, when the amount of renewable energy generated exceeds the consumption of the load, the excessive energy can be stored in the storage device, thus enabling the use of the uncontrollable power generation from renewable energy sources efficiently

Manuscript received Mar. 26, 2012 ; revised Jan. 12, 2013

Recommended for publication by Associate Editor Yujin Song.

${ }^{\dagger}$ Corresponding Author: wait4u@ssu.ac.kr

Tel: +82-2-828-7269, Fax: +82-2-817-7961, Soongsil University

*Dept. of Electrical Engineering, Soongsil University, Korea and stably [10].

In this paper, the principle operating and compensator design guidelines of the proposed scheme are presented, along with a performance analysis based on small signal modeling including the energy storage device during stand-alone operation. Numerical analyses using MATLAB and PSIM are also included to verify the model. Finally, a $1 \mathrm{~kW}$ hardware prototype of the power conditioning system with an energy storage device has been implemented for experimental verification of the proposed power conditioning system's analysis and design guidelines.

\section{A. Existed System Configuration}

In general, power conditioning systems with renewable energy sources consists of two-stage main power converters that provide renewable energy to the power grid as shown in Fig. 1. In this case, the two-stage main power converter consists of a boost converter and a grid-connected inverter [11], [12]. In addition, the AC voltage in the grid-connected mode is fixed by the grid [13]-[15].

The boost converter of the two-stage power conditioning system controls the voltage of the renewable energy source at the MPP (Maximum Power Point) and the DC-link voltage is controlled by the inverter [16]-[19]. For the extension of the power utilization, an energy storage subsystem including a bidirectional charger/discharger can be included [20]. Fig. 2 


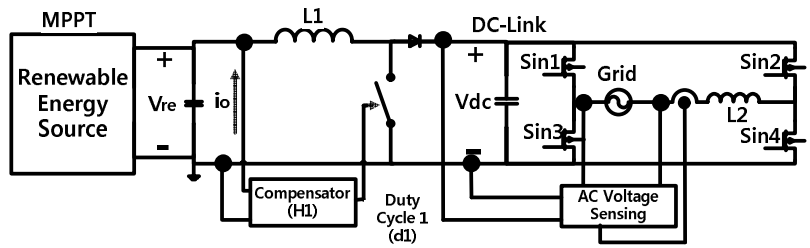

Fig. 1. Normal Circuit of the Power Conditioning System with a Renewable Source at Grid-Connected Operation.

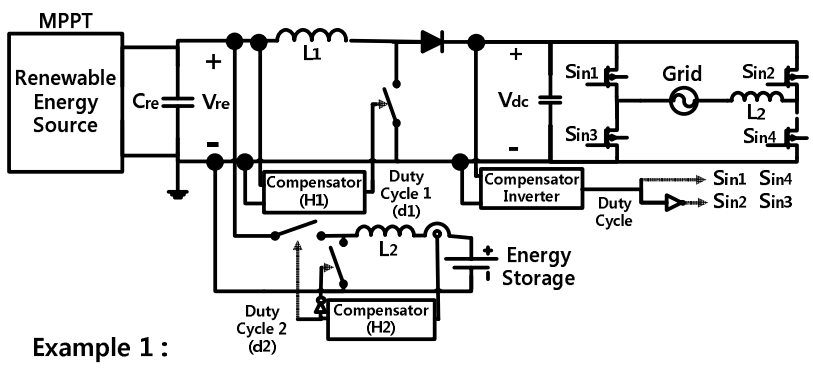

Fig. 2. Example I: Conventional Circuit of the Power Conditioning System with a Renewable Energy Source and an Energy Storage Device at Grid-Connected Operation (Front-connection).

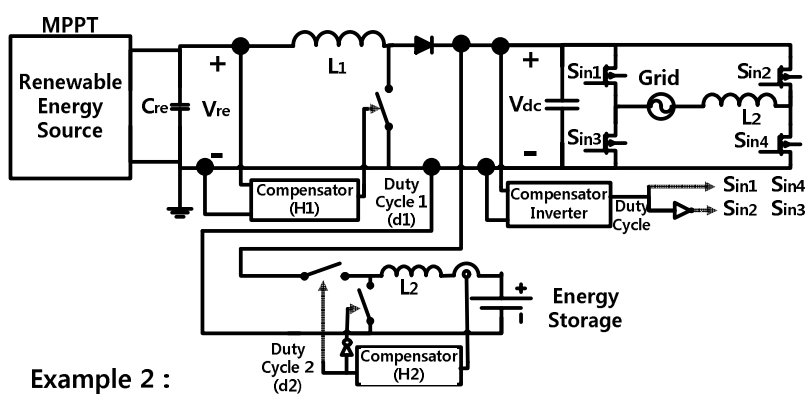

Fig. 3. Example II : Conventional Circuit of the Power Conditioning System with a Renewable Energy Source and an Energy Storage Device at Grid-Connected Operation (Middle-connection).

and Fig. 3 are the conventional circuits of power conditioning systems with an energy storage device and renewable sources [21]. Figure 2 is a conventional scheme attaching a charger/discharger at the output of the renewable energy source [22], [23]. This circuit has a disadvantage since the power capacity of the boost converter must be greater than the maximum power of the renewable energy source and discharging power from the energy storage device. In addition, since the discharging energy from the energy storage must pass the two power conversion stages of the power conditioner, the power efficiency of this system decreases significantly during the discharging mode. Figure 3 is another scheme attaching a charger/discharger at the DC-link. This scheme allows the power rating to be the maximum power of the renewable energy source, when the boost converter is designed. However, since the charging current must pass by the boost converter, the power efficiency decreases significantly during the charging mode [24]-[28].

\section{B. Proposed System Configuration}

Figure 4 shows the configuration of the proposed power conditioning system which consists of a renewable energy source and an energy storage device. The new charger/discharger scheme in this paper promises improvement in efficiency. The scheme shortens the power flow path, because the power flow has different charging and discharging paths, which eliminates the redundant power process. The proposed power conditioning system is shown in Fig. 4. Figure 5 and Fig. 6 show the power flow of the power conditioning system (PCS) in the charging and discharging modes, respectively. As shown in Fig. 5, the PCS can directly charge the energy from the renewable energy source to an energy storage device during the charging mode, due to the electrical conduction diode $\left(\mathrm{D}_{\mathrm{Chg}}\right)$. On the other hand, it can directly discharge energy the energy storage to the DC-link, due to the different conduction diode (D Dchg) as shown in Fig. 6.

Through the shortcut, energy can be stored and released more efficiently, reducing the power conversion loss. The boost converter's power capacity is fixed at the maximum power of the source by bypassing the power flow of the storage device through the discharge diode ( $\left.D_{\text {Dchg }}\right)$. Furthermore, since the shortcut path is implemented only with two extra diodes, the scheme has strong cost-competitiveness and low volume stress. However, because the boost converter in the main power stream operates simultaneously with the energy storage power converter, the controller design of the sub systems is quite complicated. For stable feedback controller design, small-signal modeling of the subsystems and a dynamic interaction analysis between the systems should be done.

Figure 4 also presents the control structure of the entire system including the regulation of the DC-link voltage and the control of the energy storage. The grid-connected inverter controls the grid-injected current and the DC-link at the same time through a two-loop controller with conventional linear feedback and feed-forward controllers. Then, the boost converter regulates the PV voltage with a voltage feedback controller using a conventional PI controller. The reference comes from the MPPT controller in the upper control layer. The energy storage system controls the inductor current to regulate the charging and discharging current. Since the purpose of the storage system is to stabilize the injected power from the renewable energy system, the reference is given from the main controller monitoring the inverter output. If the power fluctuates, the storage absorbs the fluctuation and the low frequency power is delivered to the inverter. When the fluctuation stops, the storage can charge or discharge the PV current according to its battery management systems (BMS). The role of the BMS is to operate the energy storage within a safe operating range according to the optimized SOC and $\mathrm{SOH}$ profiles. 


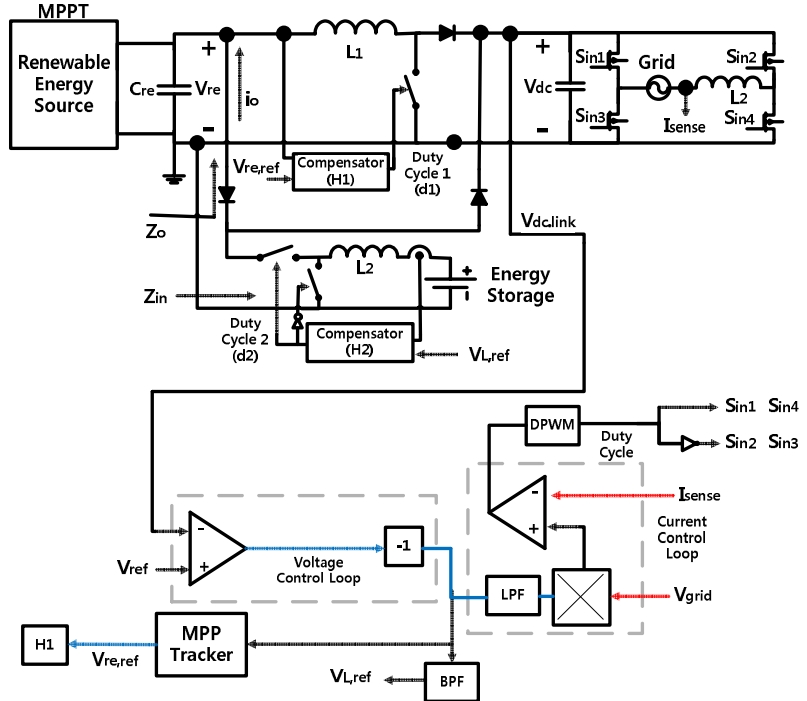

Fig. 4. Proposed Circuit of the Power Conditioning System with an energy storage device at Grid-Connected operation.

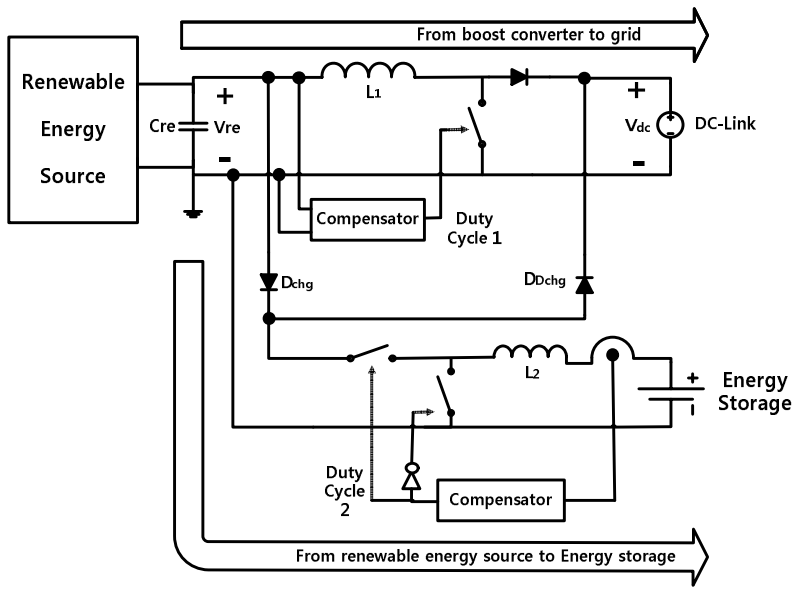

Fig. 5. Power Flow of the Power Conditioning System with an energy storage device at charging mode.

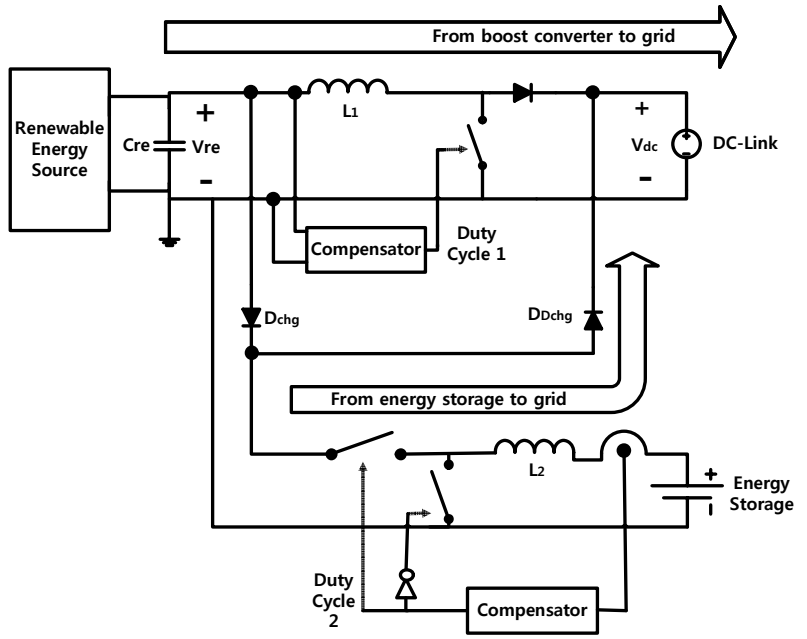

Fig. 6. Power Flow of the Power Conditioning System with an energy storage device at discharging mode.

In the following sections, the dynamic response and the design procedure of the grid-connected photovoltaic power system will be analyzed. Since the discharging circuit is very simple and the controller design is straight forward, only the charging mode will be considered.

\section{SMALl Signal Modelling}

\section{A. Analysis and Design Procedure}

The purpose of the dynamic analysis and compensator design during grid-connected operation is to determine whether the dynamic interaction between the boost converter and the charger/discharger is negligible or not. In order to design the compensator and verify the design results including the dynamic interaction, an iterative design procedure is required because of the dynamic interaction between the main power conditioner (boost) and the storage system (charger/discharger). For example, if the dynamic analysis and design begin with the boost converter, then the boost converter can have some deviations from the actual hardware since there can be some interaction from the storage part of the real hardware. If they begin with the charger/discharger, then the design results of the part can also have some errors due to the absence of the interaction consideration. Therefore, the most reliable design procedure is to start with a certain converter, and then check the final results through a comparison with the other way of starting with the other converter. For reliable design and for verification, the design procedure is as follows.

The first step is to start with the design of the compensator in the boost converter without the dynamic interaction from the charger/discharger, and also to derive its closed-loop output impedance (Section B). Then, the compensator of the charger/discharger including the dynamic interaction from the boost converter is designed for stable control operation (Section C). This is the complete design procedure for each of the controllers in the entire power system.

The next step is to verify the previous design results. Restart with the dynamic analysis of the charger/discharger without the dynamic interaction from the boost converter, and also derive its closed-loop input admittance (Section D). Then, the final control stability of the boost converter including the dynamic interaction from the charger/discharger must be considered (Section E).

Finally, the influence of the interaction is investigated by comparing the frequency response of the transfer functions between excluding and including the dynamic interaction (Section III). In following section, each of the transfer functions is derived, and the comparison results are presented with a bode-plot of the frequency response.

When designing the boost converter with the renewable energy source, the DC-link has a high capacitance to reduce $120 \mathrm{~Hz}$ ripple reflecting the AC current. Therefore, the DClink can be modeled as a DC-voltage sink which significantly simplifies the entire dynamic response model.

\section{B. Control-to-output Transfer Function and Output Impedance of the Boost Converter}




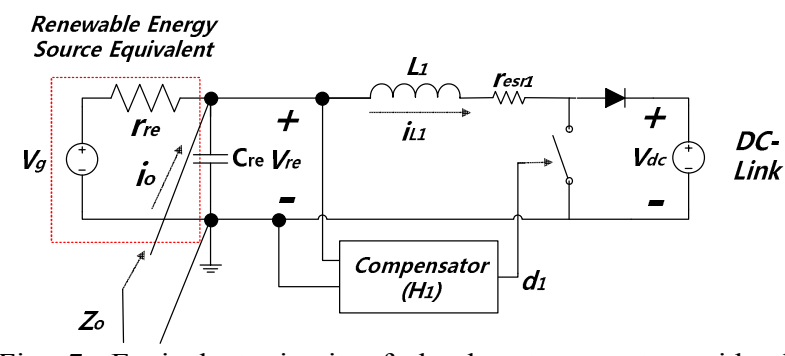

Fig. 7. Equivalent circuit of the boost converter with the renewable energy source.

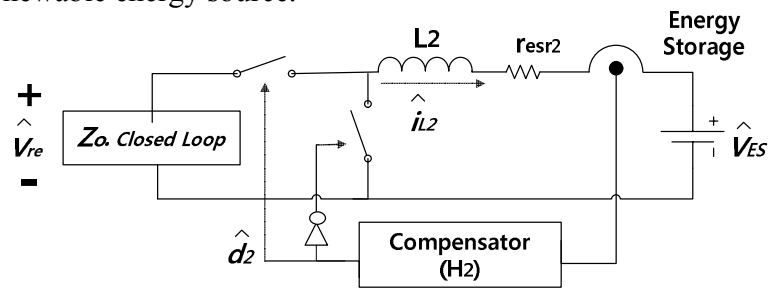

Fig. 8. Small signal model of the charger/discharger including the boost converter with the renewable energy source.

Figure 7 is the simplified equivalent circuit of the boost converter [29]. In this case, the boost converter includes a renewable energy source. To know the effect of the renewable energy source, it is replaced to the equivalent circuit as shown in Fig.7.

Control-to-output transfer function $\left(\mathrm{G}_{\mathrm{V}_{\mathrm{re}} \mathrm{d}_{1}}\right)$ of the boost converter can be derived as Eq. (1) through small-signal modeling in Fig. 7 [30]-[33].

$$
\begin{gathered}
\mathrm{G}_{\mathrm{V}_{\mathrm{re}} \mathrm{d}_{1}}=\frac{\widehat{\mathrm{v}}_{\mathrm{re}}}{\widehat{\mathrm{d}}_{1}}=-\frac{\mathrm{v}_{\mathrm{dc}}}{1+\mathrm{A}_{\mathrm{Cre}_{\mathrm{re}}} \mathrm{Z}_{\mathrm{L}_{1}}} \\
\left(\begin{array}{c}
\mathrm{Z}_{\mathrm{L}_{1}}=\mathrm{s} \mathrm{L}_{1}+\mathrm{r}_{\mathrm{es} 1} \\
\mathrm{~A}_{\mathrm{C}_{\mathrm{re}}}=\mathrm{sC}_{\mathrm{re}}+\frac{1}{\mathrm{r}_{\mathrm{re}}} \\
\mathrm{D}_{1}^{\prime}=1-\mathrm{D}_{1}
\end{array}\right)
\end{gathered}
$$

Then, the compensator of the boost converter can be designed as in Eq. (2), where Eq. (2) is a PI compensator. All of the compensators in this paper are designed as PI compensators [34]. In this case, the sensing gain, the sampling effect and the PWM gain are considered to be included in the coefficient of the proportional gain $\mathrm{K}_{\mathrm{p}}$. The controller was implemented with a digital-signal processor (TMS28335, Texas Instrument).

$$
\mathrm{G}_{\mathrm{com}}=\mathrm{K}_{\mathrm{p}}\left(1+\frac{\mathrm{K}_{\mathrm{i}}}{\mathrm{s}}\right)=\mathrm{H}_{1}=\mathrm{H}_{2}=\mathrm{H}_{3}
$$

$\mathrm{K}_{\mathrm{p}}$ : Proportional gain

$\mathrm{K}_{\mathrm{i}}$ : Intergrator gain

$\mathrm{H}_{1}$ : Compensator of the boost converter during grid - connected and stand - alone operation

$\mathrm{H}_{2}$ : Compensotor of inductor current in the charger/discharger during grid - connected and stand - alone operation

$\mathrm{H}_{3}$ : Compensator of voltage loop in the charger/discharger at charging mode during stand - alone operation

To design the compensator of the charger/discharger in connection with a boost converter with a renewable energy source, the charger/discharger must consider the dynamic

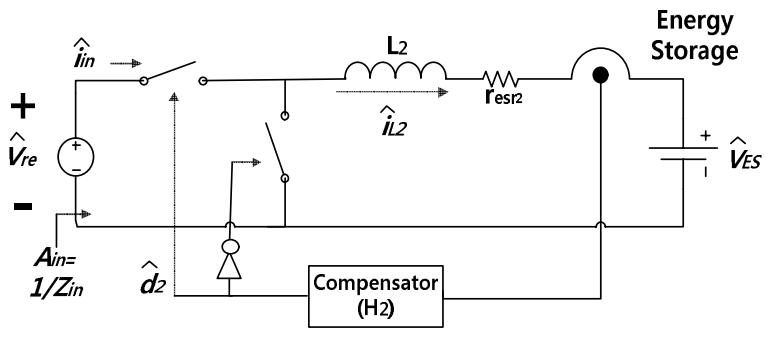

Fig. 9. Small signal model of the charger/discharger at charging mode.

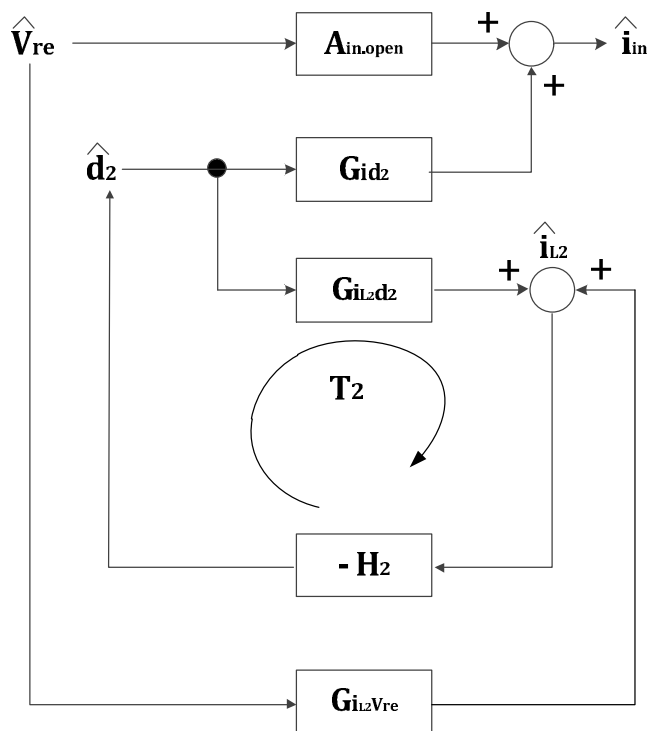

Fig. 10. Small-signal block diagram for the closed loop input admittance of the charger/discharger.

interaction of the boost converter. The dynamic interaction is considered as the output impedance of the boost converter.

First, the open-loop output impedance $\left(\mathrm{Z}_{\text {o.open }}\right)$ of the boost converter with a renewable energy source can be derived as Eq. (3) through the small-signal modeling in Fig. 7.

$$
\mathrm{Z}_{\text {o.Open Loop }}=\frac{\widehat{v}_{\text {re }}}{\hat{\mathrm{i}}_{\mathrm{o}}}=\frac{\mathrm{Z}_{\mathrm{L}_{1}}}{\mathrm{Z}_{\mathrm{L}_{1}} \mathrm{~A}_{\mathrm{C}_{\mathrm{re}}}+1}
$$

After closing the feedback loop for the voltage of the renewable source, the output impedance $\left(\mathrm{Z}_{\text {o.dsed }}\right)$ of the boost converter can be derived as Eq. (4).

$$
\mathrm{Z}_{\mathrm{o} . \text { Cbsed }}=\frac{\mathrm{Z}_{\mathrm{o.Open}}}{1+\mathrm{T}_{1}}
$$

$\left(T_{1}:\right.$ Loop gain of the boost comventer $\left.\left(=G_{v_{r e} d_{1}} H_{1}\right)\right)$

C. Control-to-output Transfer Function of the Charger/Discharger Including the Boost Converter with the Renewable Energy Source

$$
\left(\begin{array}{cc}
\mathrm{G}_{\mathrm{id}_{2}} \quad \begin{array}{c}
: \text { Control to input current } \\
\text { of the charger/discharger }
\end{array} \\
\mathrm{G}_{\mathrm{i}_{\mathrm{L}_{2}} \mathrm{v}_{\mathrm{re}}}: \text { the renewable source voltage to inductor current } \\
\text { of the charger/discharger } \\
\mathrm{G}_{\mathrm{i}_{\mathrm{L}_{2}} \mathrm{~d}_{2}}: \begin{array}{l}
\text { Control to inductor current } \\
\text { of the charger/discharger }
\end{array}
\end{array}\right)
$$




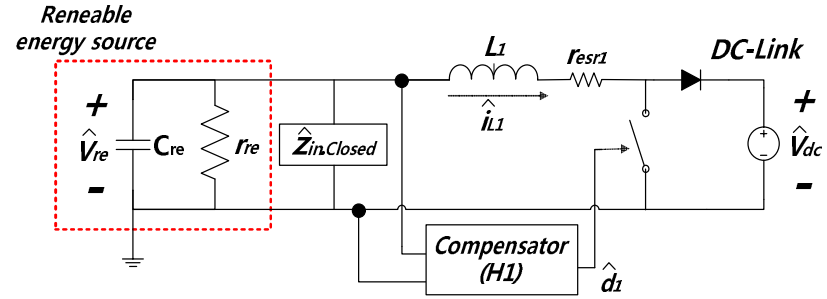

Fig. 11. Small signal model of boost converter including the charger/discharger.

As shown in Fig. 8, the control-to-output transfer function $\left(\mathrm{G}_{\mathrm{i}_{\mathrm{L}_{2}} \mathrm{~d}_{2}}\right)$ of the charger/discharger including the dynamic interaction of the boost converter with the renewable energy source closing the feedback loop must be derived. Finally, the loop gain $\left(\mathrm{T}_{2}\right)$ of the charger/discharger can be derived using Eq. (6) including the dynamic interaction of the boost converter with a renewable energy source.

$$
\begin{gathered}
\mathrm{G}_{\mathrm{i}_{\mathrm{L}_{2}} \mathrm{~d}_{2}}=\frac{\hat{\mathrm{i}}_{\mathrm{L}_{2}}}{\widehat{\mathrm{d}}_{2}}=\frac{\mathrm{V}_{\mathrm{re}}-\mathrm{D}_{2} \mathrm{I}_{\mathrm{L}_{2}} \mathrm{Z}_{\text {o.Cbsed }}}{\mathrm{Z}_{\mathrm{L}_{2}}+\mathrm{D}_{2}{ }^{2} \mathrm{Z}_{\text {o.Cbsed }}} \\
\left(\mathrm{Z}_{\mathrm{L}_{2}}=\mathrm{s} \mathrm{L_{2 }}+\mathrm{r}_{\mathrm{es} 2}\right) \\
\mathrm{T}_{2}=\mathrm{G}_{\mathrm{i}_{\mathrm{L}_{2}} \mathrm{~d}_{2}} \mathrm{H}_{2}
\end{gathered}
$$

D. Control-to-output Transfer Function and the Input Admittance of the Charger/Discharger

Figure 9 is the equivalent circuit of the charger/discharger without the dynamic interaction of the boost converter with the renewable energy source during the charging mode. The control-to-output transfer function $\left(\mathrm{G}_{\mathrm{i}_{\mathrm{L} 2} \mathrm{~d}_{2}}\right)$ can be derived as Eq. (7).

$$
\mathrm{G}_{\mathrm{i}_{\mathrm{L} 2} \mathrm{~d}_{2}}=\frac{\mathrm{V}_{\mathrm{re}}}{\mathrm{z}_{\mathrm{L}_{2}}}
$$

In addition, the open loop input admittance $\left(A_{n}\right.$.open $)$ of the charger/discharger can be derived as Eq. (8) through small-signal modeling.

$$
\mathrm{A}_{\text {in .Open }}=\frac{1}{\mathrm{Z}_{\text {n .open }}}=\frac{D_{2}^{2}}{\mathrm{Z}_{\mathrm{L}_{2}}}
$$

Then the closed-loop input admittance $\left(A_{n}\right.$.cbsed $)$ of the charger/discharger is verified as Eq. (6)-(9) by using the block diagram of Fig. 10.

$$
\begin{aligned}
& A_{\text {in .Cbsed }}=\frac{1}{Z_{\text {n .Cbsed }}}=A_{\text {in .Open }}-G_{i_{2}} H_{2} \frac{{ }_{2}{ }_{i_{L_{2}}} v_{\text {re }}}{1+T_{2}} \\
& \mathrm{G}_{\mathrm{id}_{2}}=\frac{\hat{\mathrm{h}}_{\mathrm{h}}}{\widehat{\mathrm{d}}_{2}}=\frac{\mathrm{D}_{2} \mathrm{~V}_{\mathrm{re}}}{\mathrm{Z}_{\mathrm{L}_{2}}}+\mathrm{I}_{\mathrm{L}_{2}} \\
& \mathrm{G}_{\mathrm{i}_{\mathrm{L}_{2}} \mathrm{v}_{\mathrm{re}}}=\frac{\hat{\mathrm{1}}_{\mathrm{L}_{2}}}{\widehat{\mathrm{v}}_{\mathrm{re}}}=\frac{\mathrm{D}_{2}}{\mathrm{Z}_{\mathrm{L}_{2}}} \\
& \mathrm{G}_{\mathrm{i}_{\mathrm{L} 2} \mathrm{~d}_{2}}=\frac{\hat{\mathrm{L}}_{\mathrm{L}_{2}}}{\hat{\mathrm{d}}_{2}}=\frac{\mathrm{V}_{\mathrm{re}}}{\mathrm{Z}_{\mathrm{L}_{2}}}
\end{aligned}
$$

\begin{tabular}{|c|c|c|c|}
\hline $\mathrm{V}_{g}$ & $300 \mathrm{~V}$ & $\mathrm{~V}_{d c}$ & $320 \mathrm{~V}$ \\
\hline $\mathrm{V}_{r e}$ & $150 \mathrm{~V}$ & $\mathrm{~V}_{\text {Energy -storage }}$ & $\begin{array}{c}50- \\
100 \mathrm{~V}\end{array}$ \\
\hline$R_{g}$ & $45 \Omega$ & $\mathrm{R}_{d c}$ & $400 \Omega$ \\
\hline$L_{1}$ & $1.4 \mathrm{mH}$ & $L_{2}$ & $1.4 \mathrm{mH}$ \\
\hline $\mathrm{C}_{g}$ & $2200 \mu \mathrm{F}$ & $\mathrm{C}_{d c}$ & $6800 \mu \mathrm{F}$ \\
\hline$r_{e s r} 1$ & $0.3 \Omega$ & $r_{e s r 2}$ & $0.3 \Omega$ \\
\hline $\mathrm{f}_{s w, b o o s t}$ & $20 \mathrm{KHz}$ & $\mathrm{f}_{s w, \text { bidrectional }}$ & $40 \mathrm{KHz}$ \\
\hline
\end{tabular}

E. Control-to-output Transfer Function of the Boost Converter Including the Charger/Discharger

In order to know the effect on the boost converter from the charger/discharger, the input impedance ( $\left.\mathrm{Z}_{\mathrm{n} \text {.Cbsed }}\right)$ of the charger/discharger in the closed loop must be applied as
TABLE I

Key ElEMENT DAta

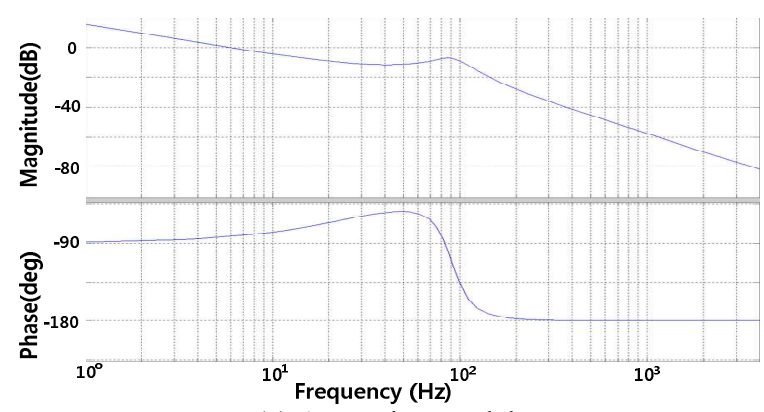

(a) Averaging model.

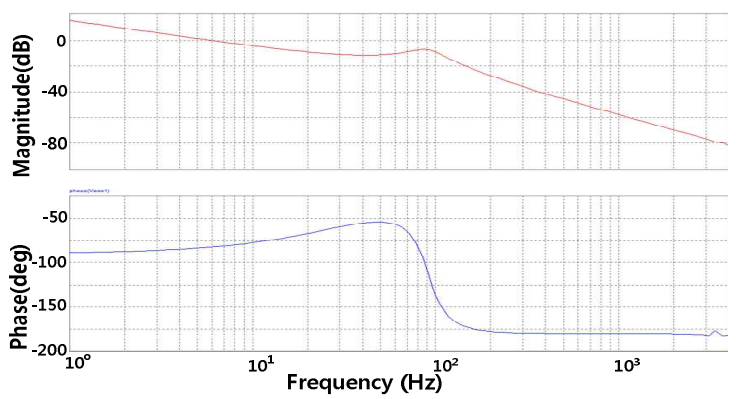

(b) Exact switching model.

Fig. 12. Loop gain of the boost converter without dynamic interaction of the charger/discharger.

shown in Fig. 11. The control-to-output transfer function $\left(G_{v_{r e} d_{1}}\right)$ of the boost converter including the dynamic interaction of the charger/discharger can be derived as Eq. (13).

$$
\begin{gathered}
\mathrm{G}_{\mathrm{v}_{\mathrm{re}} \mathrm{d}_{1}}=\frac{\widehat{\mathrm{v}}_{\mathrm{re}}}{\widehat{\mathrm{d}}_{1}}=-\frac{\mathrm{v}_{\mathrm{dc}}}{1+\mathrm{A}_{\mathrm{re}} \mathrm{Z}_{\mathrm{L}_{1}}} \\
\left(A_{r e}=A_{C_{r e}} \| \mathrm{Z}_{\mathrm{n} \text {.Cbsed }}\right)
\end{gathered}
$$

Then, the dynamic performance of the boost compensator designed in Section II.C can be checked with this transfer function.

\section{SIMULATION RESULTS}

In this section, simulations of the boost converter and the charger/discharger including their dynamic interactions on each other are done for a stability analysis using a bode-plot. This paper compares a MATLAB simulation based on the equations of the transfer function with the frequency response 


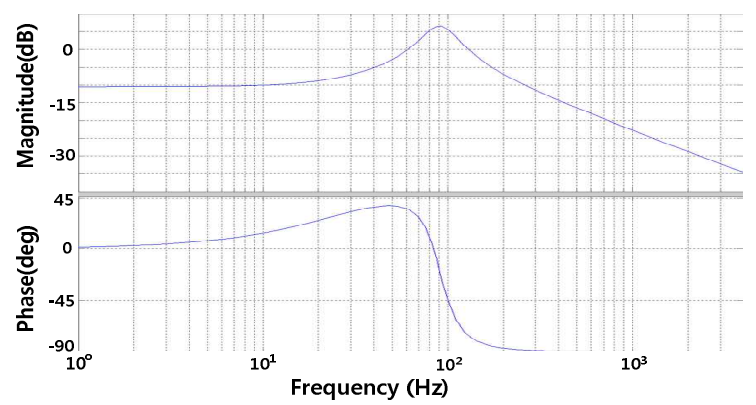

(a) Averaging model.

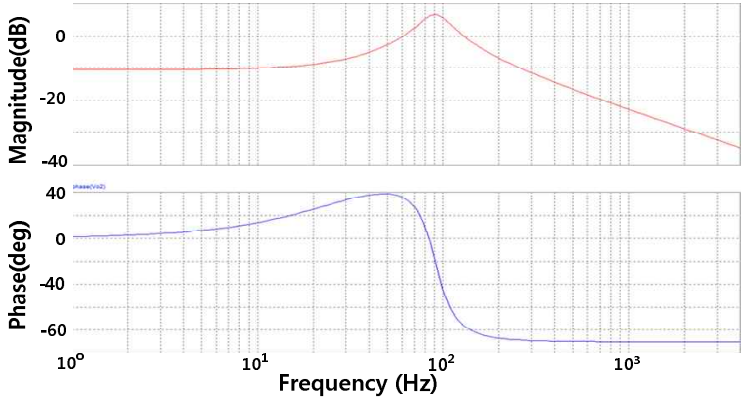

(b) Exact switching model.

Fig. 13. Closed loop output impedance of the boost converter without the dynamic interaction of the charger/discharger.

of a PSIM based on the exact PWM switching circuit to verify the previous derivation results. Table I shows the key parameters of the simulation, which are the same as those used for the hardware experiment. For the small-signal analysis, the inductor current of the charger/discharger is $1 \mathrm{~A}$ as the bias condition.

\section{A. Frequency Response Analysis}

Fig. 12 is loop gain of the boost converter without the dynamic interaction of the charger/discharger. As shown in Fig. 12, the phase margin of the closed loop in the boost converter without the dynamic interaction of the charger/discharger is high enough at greater than $90^{\circ}$.

Then, the output impedance of the boost converter with the renewable source including the effect from the charger/discharger on the boost converter is shown in Fig. 13.

The loop gain of the charger/discharger including the dynamic interaction of the boost converter is shown in Fig. 14. As shown in Fig. 14, the phase margin of the closed loop of the charger/discharger including the dynamic interaction of the boost converter with the renewable energy source is high enough at greater than $80^{\circ}$.

Next, the closed loop gain of the charger/discharger without the dynamic interaction of the boost converter with the renewable energy source is shown in Fig. 15. The phase margin of the closed loop of the charger/discharger without the dynamic interaction of the boost converter with the renewable energy source is high enough at greater than $80^{\circ}$. The input admittance of the charger/discharger is shown in Fig.

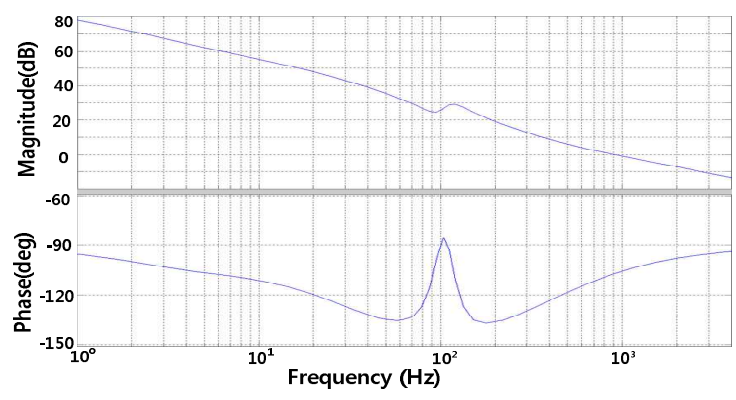

(a) Averaging model.
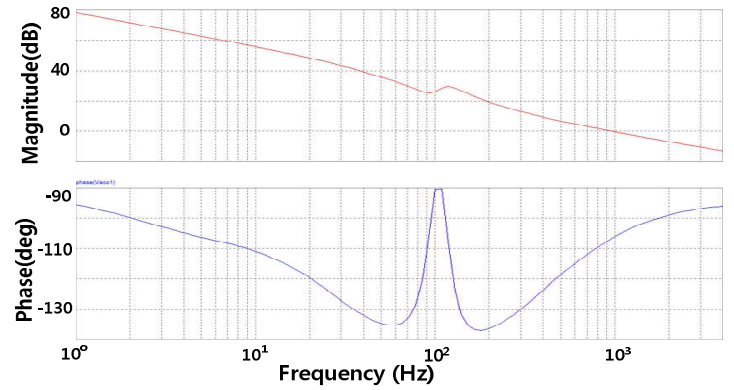

(b) Exact switching model.

Fig. 14. Loop gain of the charger/discharger including dynamic interaction of the boost converter.

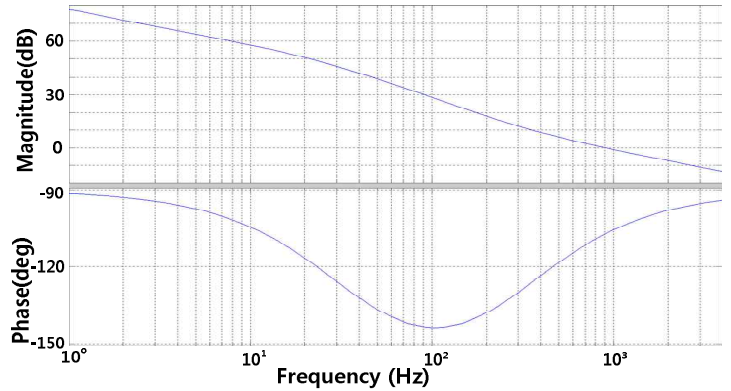

(a) Averaging model.

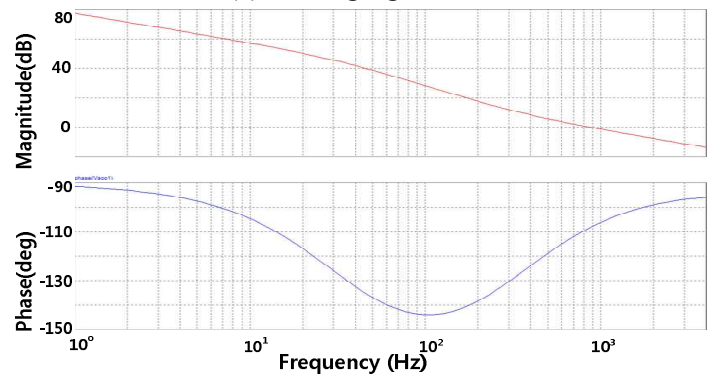

(b) Exact switching model.

Fig. 15. Loop gain of the charger/discharger without dynamic interaction of the boost converter.

16 including the effect from charger/discharger on the boost converter.

Then, the closed loop of the boost converter including the dynamic interaction of the charger/discharger is shown in Fig. 17. Fig. 17 shows the loop gain of the boost converter including the dynamic interaction of the charger/discharger. The phase margin of the closed loop of the charger/discharger including the dynamic interaction of the boost converter with the renewable energy source is high enough at greater than $90^{\circ}$. 


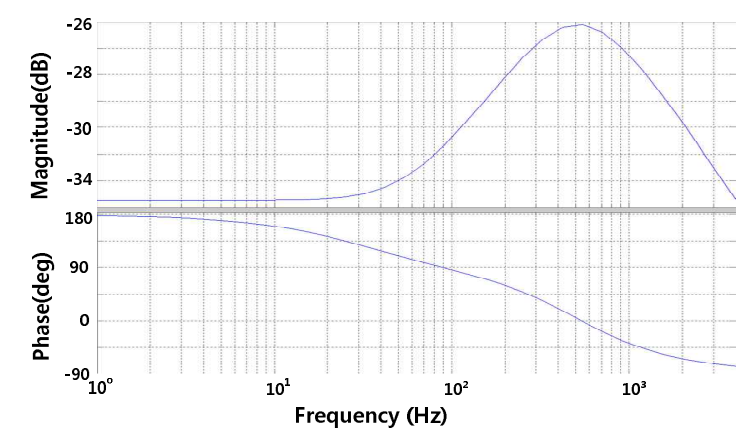

Fig. 16. Input admittance of the charger/discharger without the dynamic interaction of the boost converter. (Averaging model)

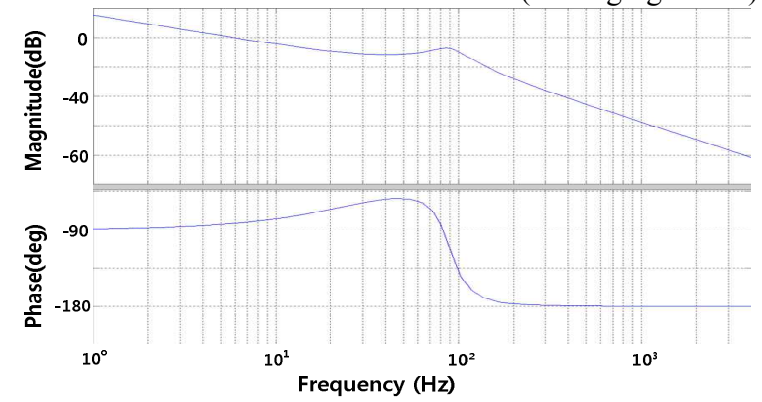

(a) Averaging model.

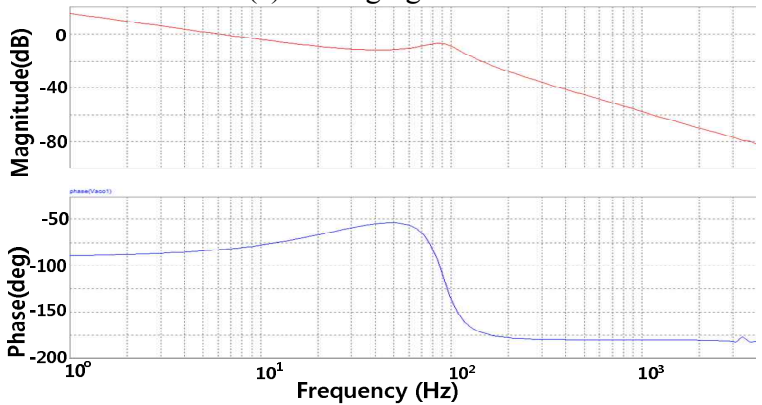

(b) Exact switching model.

Fig. 17. Closed loop gain of the boost converter including dynamic interaction of the charger/discharger.

TABLE II

CONTROLLER DATA

\begin{tabular}{|c|c|c|c|}
\hline \multicolumn{2}{|c|}{ BOOST CONVERTER } & \multicolumn{2}{|c|}{ CHARGER/DISCHARGER } \\
\hline $\mathrm{P}$ gain & -0.0005 & $P$ gain & 0.05 \\
\hline I gain & 0.0083 & I gain & 0.0005 \\
\hline
\end{tabular}

In all of the results of the figures regarding frequency response, the state-space averaged model is in good agreement with the simulation based on the exact switching model.

When comparing Fig. 14 and Fig. 15, it is shown that the compensator design of the charger/discharger is significantly affected by the dynamic interaction of the boost converter. However, when comparing Fig. 12 and Fig. 17, it is shown that compensator design of the boost converter is not seriously affected by the dynamic interaction of the charger/discharger.

These results mean that the boost converter design should be done before the charger/discharger design. If the charger/discharger is designed first, the dynamic response of

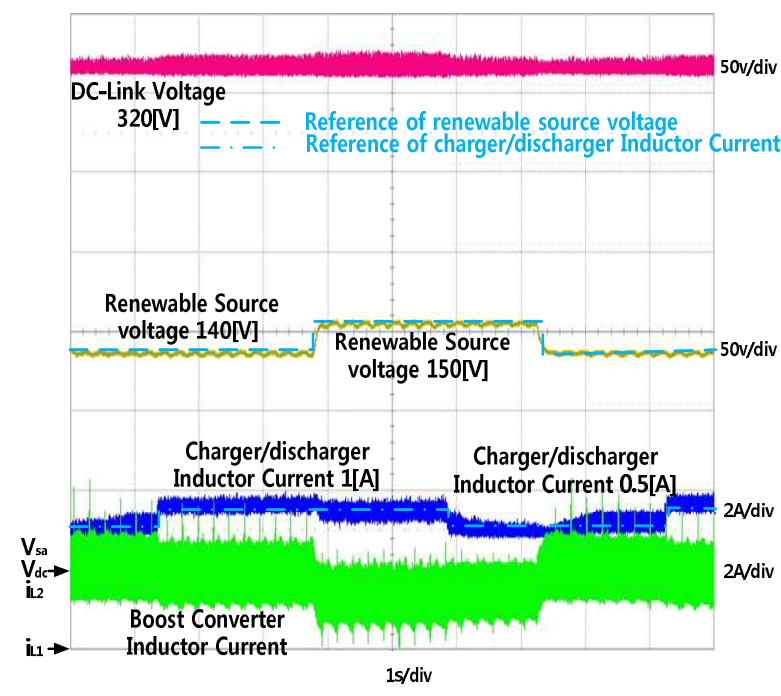

Fig. 18. Step response of the output voltage of renewable energy source and inductor current of the charger/discharger.

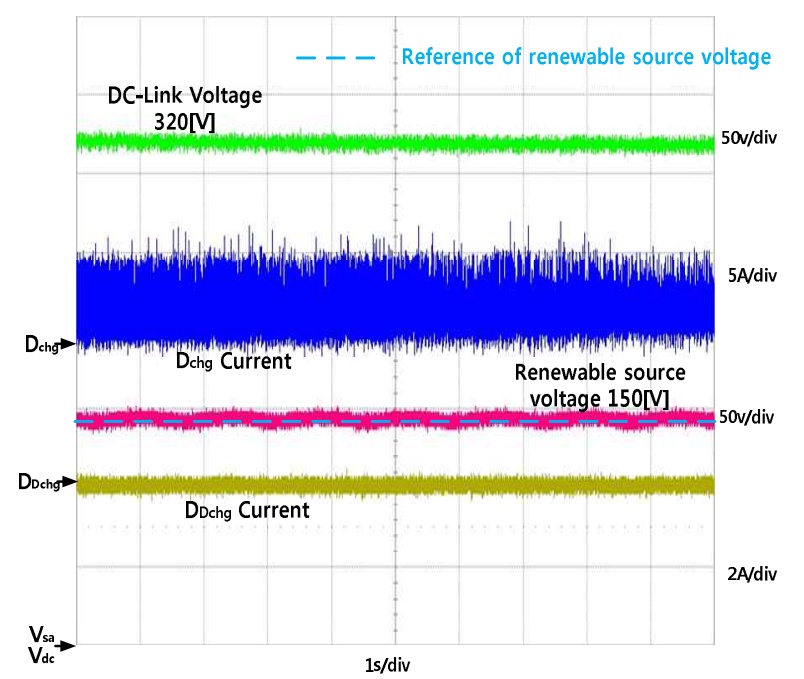

Fig. 19. Current of charging diode $\left(D_{\text {chg }}\right)$ and discharging diode $\left(D_{\mathrm{D} d g}\right)$ at charging mode.

the boost converter must be considered carefully. Table II shows the gain parameters of the controllers.

\section{EXPERIMENTAL RESULTS}

Figure 18 shows the experimental waveforms regarding the voltage of the renewable energy source and the DC-link along with the inductor current of the charger/discharger and the boost converter.

This figure shows that the reference for the output voltage of the renewable energy source is step-changed from $140 \mathrm{~V}$ to $150 \mathrm{~V}$ at the same time that the inductor current of the charger/discharger is step-changed from $1 \mathrm{~A}$ to $0.5 \mathrm{~A}$. These experimental results show that the grid-connected operation is well-traced and stable. Fig. 18 shows that the DC-link voltage at $320 \mathrm{~V}$ is still regulated. 


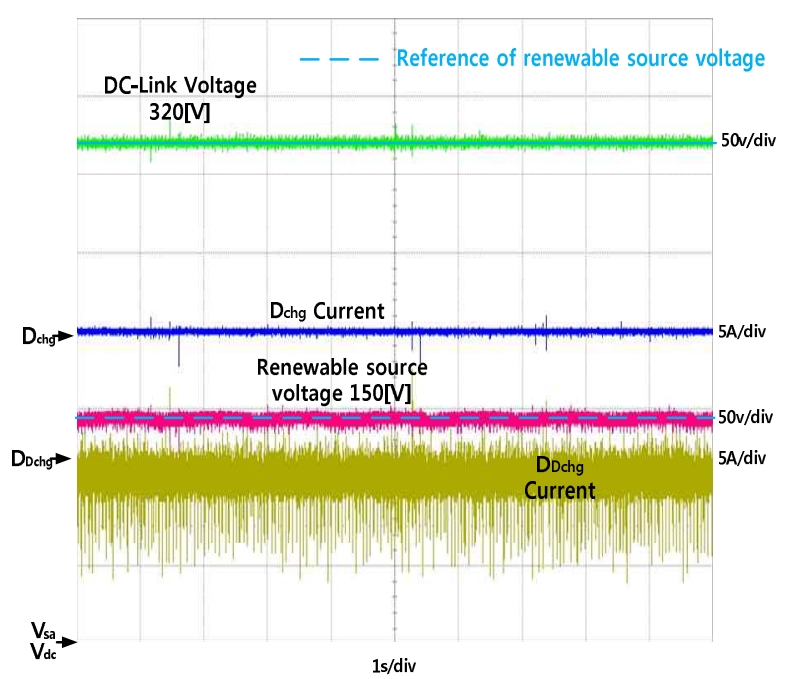

Fig. 20. Current of charging diode $\left(D_{\mathrm{chg}}\right)$ and discharging diode $\left(D_{\text {Ddhg }}\right)$ at discharging mode.

Figure 19 shows the current waveforms of both the charging diode $\left(D_{c h g}\right)$ and discharging diode $\left(D_{D \text { dg }}\right)$ in the charging mode. From the figure, it can be seen that the charging current flows only through $\mathrm{D}_{\text {chg }}$. It does not flow through $\mathrm{D}_{\text {Dchg }}$, as shown in Fig. 5.

Fig. 20 shows the current waveforms of both the charging diode $\left(D_{c h g}\right)$ and discharging diode $\left(D_{D \text { dgg }}\right)$ in the discharging mode. From the figure, it can be seen that the discharging current flows only through $\mathrm{D}_{\text {Dchg }}$. It does not flow through $D_{\text {chg }}$, as shown in Fig. 6. From these figures, it can be seen that the charging and discharging currents have different conduction paths as presented in the operating principle of the proposed scheme.

Figures 21 shows the key waveforms for checking the dynamic response of the proposed system. The charger/discharger has a step-response between the charging and discharging modes repeatedly, through the reference stepchange of the inductor current controller in the charger/discharger. From the inductor current waveform in Fig. 21 , it can be seen that the operating mode can be step-changed successfully. Input voltage of the boost converter is regulated stably even at the mode transitions. The voltage across the bottom MOSFET in the bidirectional converter shows that when it changes from the charging mode to the discharging mode, the voltage stress increases up to the DC-link due to the discharge diode turn-on. When it changes from the discharging mode to the charging mode, the stress drops down due to the charging diode conduction. From these figures, it can be concluded that the designed controller shows stable operation even under step changes of the control reference.

Table III shows the measured power efficiency of conventional systems (Fig. 2 and Fig. 3) and the proposed one (Fig. 4). The measured condition is the same as Table I. The results show that both the charging and discharging operations in the proposed scheme have relatively high efficiencies when
TABLE III

MEASURED EFFICIENCY

\begin{tabular}{|c|c|c|}
\hline & Charging & Discharging \\
\hline Figure 2 & $95.5 \%$ & $83.6 \%$ \\
\hline Figure 3 & $80.2 \%$ & $90.1 \%$ \\
\hline Figure 4 & $93.9 \%$ & $89.3 \%$ \\
\hline
\end{tabular}

C1: Voltage across the bottom MOSFET in bidirectional charger-discharger (100V/div.).

$\mathrm{C} 2$ : Energy storage voltage (100V/div.)

C3: Output current of the DC-link $(500 \mathrm{~mA} /$ div.)

$\mathrm{C} 4$ : Inductor current of the charger-discharger $(1 \mathrm{~A} /$ div. $)$

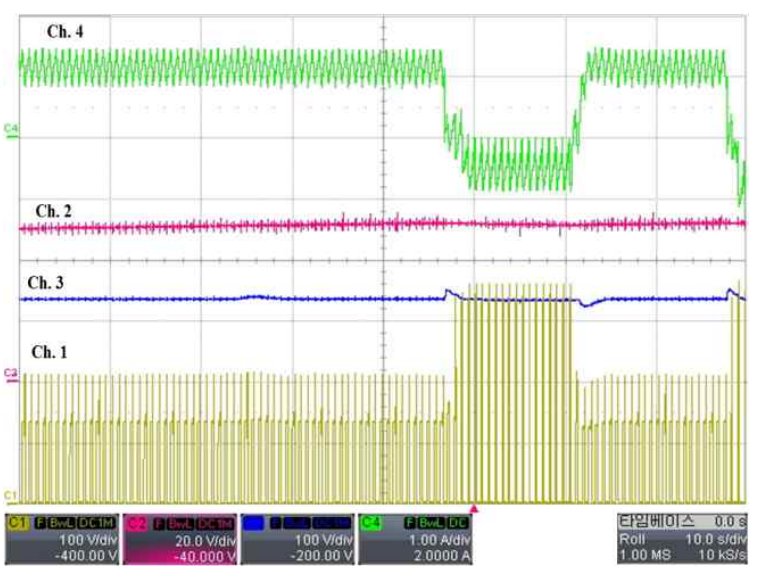

Fig. 21. Key waveforms of the hardware during the steptransition including the input voltage of the boost converter.

C1: Voltage across the bottom MOSFET in bidirectional charger-discharger (100V/div.).

C2: Energy storage voltage (20V/div.)

C3: Input voltage of the boost converter $(100 \mathrm{~V} / \mathrm{div}$.)

C4: Inductor current of the charger-discharger (1A/div.)

compared to the conventional schemes. The small amount of efficiency reduction $\mathrm{i} n$ the proposed scheme when compared to the highest value is from the bypass diode conduction loss.

For a more detailed analysis, the temperature distributions of the hardware prototypes were measured and presented in Fig. 22. In the experiment, the conversion losses of the bi-directional charger/discharger from the PV source to the energy storage and from the DC-link to the energy storage were investigated. The surface temperatures of the components were measured by a Thermal Imaging Camera DM-60, Zhejiang Dali Technology Co., Ltd. The infrared thermography system consists mainly of a camera and software for converting the recorded information to a temperature signal.

Fig. 22(a) and 22(b) show the temperature distribution of the two conditions. The experiment was done at ambient temperature. As shown in the thermal images, the spot of the heat source is shown as a cross with the number 1 . The number shown in the right upper section of the window is the steady-state temperature measured at the spot. The experimental results show that the temperature of the bidirectional inductor in the charger/discharger rises up to 


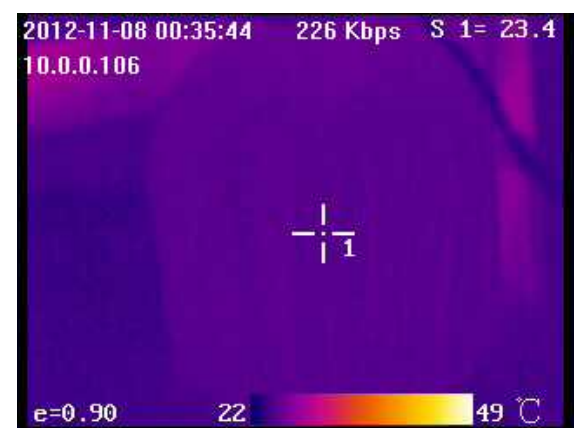

(a) From the PV source to energy storage $(150 \mathrm{~V} / 50 \mathrm{~V})$. 2012-11-07 22:02:01 216 Kbps S $1=27.2$ 10.0.0.106

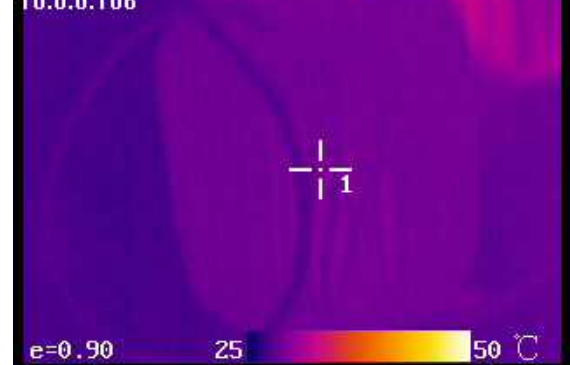

(b) From DC-link to energy storage (320V / 50V).

Fig. 22. Comparison of the thermal distribution of the hardware.

$23.4^{\circ} \mathrm{C}$ (See Fig. 22(a)) when the charging current flows from the PV source to the storage. On the other hand, in charging from the DC-link, the temperature rises up to $27.2^{\circ} \mathrm{C}$ (See Fig. 22(b)). This loss reduction significantly contributes the efficiency improvement of the proposed scheme. From the experimental results, it is concluded that the proposed scheme is effective for improving conversion efficiency.

\section{CONCLUSIONS}

Using small signal modeling of the power conditioning system with an energy storage device, control loops were designed for the overall system, including the dynamic interaction analysis between the charger/discharger and the boost converter. Stable operation of the energy flow from a renewable energy source to the grid is achieved.

For a stable compensator design, this paper considered the input/output impedance of each converter for the dynamic interaction between the boost converter and the charger/discharger. The analysis contributed to the stable and efficient operation of the renewable-energy sourced distributed power system. The derived equations are verified by a comparison between the simulations of PSIM and MATLAB.

Finally, the analysis and design guidelines are verified through the experimental results obtained by the implementation of a $1 \mathrm{~kW}$ power conditioning system hardware prototype with an energy storage device.

\section{ACKNOWLEDGEMENT}

This work was supported by the Human Resources Development program (No. 20124010203160) of the Korea
Institute of Energy Technology Evaluation and Planning(KETEP) grant funded by the Korea government Ministry of Knowledge Economy.

\section{REFERENCES}

[1] R. Calabria, "Grid-Connected photovoltaic systems with energy storage," Clean Electrical Power, 2009 International Conference on, pp. 760 - 767, 9-11 Jun. 2009.

[2] S. Mazumder, R. Burra, and K. Acharya, "Power Conditioning System for Energy Sources," Pub. No.: US 2006/0062034 A1, Mar. 23, 2006.

[3] P. T. Krein and Jr. R. S. Balog, "Methods for Minimizing Double-Frequency Ripple Power in Single-Phase Power Conditioning," Patent No.: US 7, pp. 755, 916 B2, Jul. 13, 2010.

[4] R. S. Bhatia, D. P. Jain, D. K. Jain, and B. Singh, "Battery energy storage system for power conditioning of renewable energy sources," Power Electronics and drives systems, International conference on, pp. 501-506, Apr. 2006.

[5] R. Mittal, K. S. Sandhu, and D. K. Jain, "Battery energy storage system for variable speed driven PMSG for wind energy conversion system," Power electronics, Drives and energy systems (PEDES) \& 2010 Power India, 2010 Joint international conference on, pp.1-5, Feb. 2010.

[6] A. Goikoetxea, J. A. Barrena, M. A. Rodriguez, and G. Abad, "Grid manager design using battery energy storage systems in weak power systems with high penetration of wind energy," International conference on renewable energies and power quality, Mar. 2010.

[7] A. Izena, H. Kihara, T. Shimojo, K. Hirayama, N. Furukawa, T. Kageyama, T. Goto, and C. Okamura, "The role of energy storage for mini-grid stabilization," Power engineering society general meeting, 2006.

[8] S. Vazquez, S. M. Lukic, E. Galvan, and L. G. Franquelo, "Energy storage systems for transport and grid applications," IEEE Trans. Ind. Electron., Vol. 57, No. 12, pp. 3881-3895, Dec. 2010.

[9] J.-Y. Kim , J.-H. Jeon, and S.-K. Kim, "Coordinated Stateof-Charge Control Strategy for Microgrid during Islanded Operation," Journal of Electrical Engineering \& Technology, Vol. 7, No. 6, pp. 824-833, Nov. 2012.

[10] S.-J. Park, S. Mun, J.-H. Park, and H.-J. Jeon, “Controller design of power conditioning systems with energy storage device for renewable energy source under stand-alone operation," Applied Power Electronics Conference and Exposition, pp. 1967-1972, Feb. 2012.

[11] J.-H. Lee, J.-H. Park, and H. Jeon, "Series-connected forward-flyback converter for high step-up power conversion," IEEE Trans. Power Electron., Vol. 26, No. 12, pp. 3629-3641, Dec. 2011

[12] A.-Y. Jung, J.-H. Park, and H.-J. Jeon, “Analysis and design of phase-interleaving series-connected module-integrated converter for DC-link ripple reduction of multi-stage photovoltaic power systems," Progress In Photovoltaics: Research And Applications, Feb. 2012.

[13] J.-M. Kwon, K.-H. Nam, and B.-H. Kwon, "Photovoltaic power conditioning system with line connection," IEEE Trans. Ind. Electron., Vol. 53, No. 4, pp. 1048-1054, Jun. 2006.

[14]K. Agbossou, M. Kolhe, J. Hamelin, and T. K. Bose, "Performance of a stand-alone renewable energy system based on energy storage as hydrogen," IEEE Trans. Energy Convers., Vol. 19, No. 3, pp. 633-640, Sep. 2004.

[15]A. K. Abdelsalam, A. M. Massoud, S. Ahmed, and P. Enjeti, "High-performance adaptive perturb and observe MPPT technique for photovoltaic-based microgrids," IEEE Trans. Power Electron., Vol. 26, No. 4, pp. 1010-2021, Apr. 2011.

[16] E. M. Ahmed, "Variable step size maximum power point tracker using a single variable for stand-alone battery storage PV systems," Journal of Power Electronics, Vol. 11, No. 2, pp. 113-243, Mar. 2011. 
[17] S.-E. Lee, D.-J. Won , I.-Y. Chung, "Operation scheme for a wind farm to mitigate output power variation," Journal of Electrical Engineering \& Technology, Vol. 7, No. 6, pp. 869-875, Nov. 2012,

[18]S. Makhloufi and R. Abdessemed, "Type-2 fuzzy logic optimum $\mathrm{PV} /$ inverter sizing ratio for grid-connected PV systems," Journal of Electrical Engineering \& Technology, Vol. 6, No. 6, pp. 731-741, Nov. 2011.

[19] J.-H. Park, J.-Y. Ahn, B.-H. Cho, and G.-J. Yu, "Dualmodule-based maximum power point tracking control of photovoltaic systems," IEEE Trans. Ind. Electron., Vol. 53, No. 4, pp. 1036-1047, Jun. 2006.

[20]I.-B. Song, D.-Y. Jung, Y.-H. Ji, S.-C Choi, S-W Lee, and C.-Y. Won, "A residential $10 \mathrm{kWh}$ lithium-polymer battery energy storage system," 8th international conference on Power Electronics-ECCE Asia, pp. 2625-2630, May 2011.

[21] N. Fermia, G. Petrone, and G. Spagnulolo, "A technique for improving $\mathrm{P} \& \mathrm{O}$ MPPT performances of double-stage gridconnected photovoltaic systems," IEEE Trans. Ind. Electron. Vol. 56, No. 11, pp. 4473-4482, Nov. 2009.

[22] G.-H. Choe, H.-S. Kim, H.-S. Heo, B.-H. Jeong, Y.-H. Choi, and J.-C. Kim, "Utility Interactive PV Systems with Power Shaping Function for Increasing Peak Power Cut Effect," Journal of Power Electronics, Vol. 8 No. 4, pp. 291-382, Oct. 2008

[23] S.-J. Park, J.-H. Park, and H.-J. Jeon, "Controller design of grid-connected power conditioning system with energy storage device," Electrical Machines and Systems International Conference on, pp. 1-6, Aug. 2011.

[24]Z. Wang, G. Li, G. Li, and H. Yue, "Studies of multi-type composite energy storage for the photovoltaic generation system in a micro-grid," Electric Utility Deregulation and Restructuring and Power Technologies (DRPT), pp. 791-796, Jul. 2011

[25]M. E. Glavin, P. K. W. Chan, and W. G. Hurley, "Optimization of autonomous hybrid energy storage system for photovoltaic applications," Energy Conversion Congress and Exposition, 2009, pp.1417-1424, Sep. 2009.

[26] X. Liu, P. Wang, P. C. Loh, F. Gao, and F. H. Choo, "Control of hybrid battery/ultra-capacitor energy storage for stand-alone photovoltaic system," Energy Conversion Congress and Exposition (ECCE), 2010 IEEE, pp. 336-341, Sep. 2010.

[27] D.-H. Jang, S.-K. Ji, C.-W. Roh, S.-S. Hong, and S.-K. Han, "High power density and low cost photovoltaic power conditioning system with energy storage system," IPEC, 2010 Conference Proceedings, pp. 235-240, Oct. 2010.

[28] Y. Deng, S. Y. Foo, and H. Li, "Study of bidirectional DCDC converter interfacing energy storage for vehicle power management using real time digital simulator (RTDS)," Journal of Power Electronics, Vol. 11, No. 4, pp. 479-489, Jul. 2011.

[29]S. Mehrnami and S. Farhangi, "Innovative decision reference based algorithm for photovoltaic maximum power point tracking," Journal of Power Electronics, Vol. 10 No. 5 , pp. 528-537, Sep. 2010.

[30] S. K. Chung, "Transient characteristics of high-voltage flyback transformer operating in discontinuous conduction mode," Electric Power Applications, IEE Proceedings, Vol. 151, No. 5, pp. 628-6349, Sep. 2004.

[31] M. K. Kazimierczuk, N. Sathappan, and D. Czarkowski, "Voltage mode controlled PWM buck DC-DC converter with a proportional controller," Aerospace and Electronics Conference, NAECON 1993, Proceedings of the IEEE 1993 National, 0-7803-1295-3. pp. 413-419, May 1993.

[32] M. G. Vilalva, T. G. de Siquerira, and E. Ruppert, "Voltage regulation of photovoltaic arrays: small-signal analysis and control design," Power Electronics, IET, pp. 869-880, Nov. 2010.

[33]B. Johansson, "DC-DC Converters Dynamic Model Design and Experimental Verification," Lund University, Doctoral
Dissertation in Industrial Automation Department of Industrial Electrical Engineering and Automation. 2004.

[34] Y. Panov and M. Jovanovic, "Practical issues of input/output impedance measurements in switching power supplies and application of measured data to stability analysis," Applied Power Electronics Conference and Exposition, 2005. APEC 2005. Twentieth Annual IEEE, pp. 1339-1345, Mar. 2005.

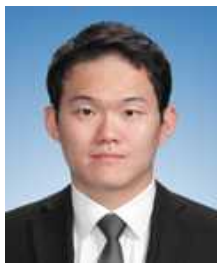

Sun-Jae Park received his B.S. and M.S. from the Department of Electrical Engineering of Soongsil University, Seoul, Korea, in 2009 and 2012, respectively. His current research interests include the analysis and design of high-frequency switching converters, etc.

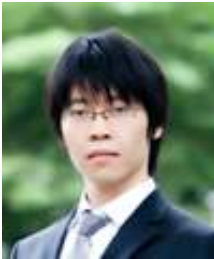

Hwa-Seok Lee received his B.S. from the Department of Electrical Engineering of Soongsil University, Seoul, Korea, in 2012. $\mathrm{He}$ is currently pursuing his M.S. at Soongsil University. His current research interests include the analysis and design of renewable energy systems, battery management, etc.

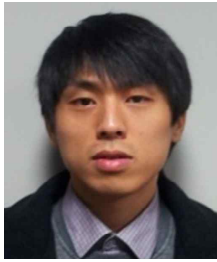

Chan-In Kim received his B.S. from the Department of Electrical Engineering of Soongsil University, Seoul, Korea, in 2011. $\mathrm{He}$ is currently pursuing his M.S. at Soongsil University. His current research interests include the analysis and design of renewable energy systems, battery management, etc.

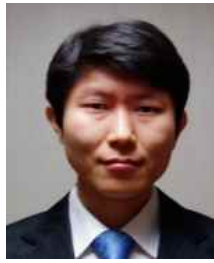

Joung-Hu Park received his B.S., M.S. and Ph.D. from the Department of Electrical Engineering and Computer Science of Seoul National University, Seoul, Korea, in 1999, 2001 and 2006, respectively. He is currently an Assistant Professor at Soongsil University, Seoul, Korea. His current research interests include the analysis of high-frequency switching converters and renewable energy

applications, etc.

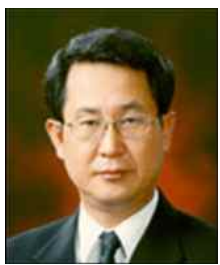

Hee-Jong Jeon received his B.S. from Soongsil University, Seoul, Korea, his M.S. from Seoul National University, Seoul, Korea, and his Ph.D. from Chung-Ang University, Seoul, Korea, in 1975, 1977 and 1987, respectively. He was a Vice President of the Korea Institute of Power Electronics from 2000 to 2001 . He is currently a Professor at Soongsil University, Seoul, Korea. His current research interests include mechatronics systems, automation control and renewable energy systems, etc.

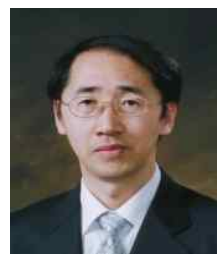

Jeongduk Ryeom received his B.S., M.S. and Ph.D. from the Department of Electrical Engineering of Seoul National University, Seoul, Korea, in 1987, 1989 and 1992, respectively. $\mathrm{He}$ is currently an Associate Professor at Soongsil University, Seoul, Korea. His current research interests include the application of high-frequency switching converters for LED lamp driving circuits, etc. 